\title{
PRESERVACIÓN DEL PATRIMONIO CULTURAL EN TÍBET: SITUACIÓN Y PERSPECTIVAS DE FUTURO DEL MONASTERIO DE THOLING
}

\author{
PRESERVATION OF CULTURAL HERITAGE IN TIBET: SITUATION AND \\ FUTURE PROSPECTS OF THE THOLING MONASTERY
}

Yin Li

Universidad Rey Juan Carlos, España

Aceptado: 10 de junio de 2020

\begin{abstract}
RESUMEN
El Monasterio de Tholing es uno de los monumentos religiosos más importantes del oeste del Tíbet; sus murales muestran el mayor logro artístico de los tibetanos en el contexto cultural y estético en los dos períodos diferentes de la historia tibetana. Este estudio presenta, en primer lugar, el contexto histórico de este monumento, indicando su importancia en el desarrollo de la historia tibetana; en segundo lugar, el valor histórico y artístico de los murales del Monasterio de Tholing. Se considera que este importante y valioso monumento debe contar con mayor atención para su investigación y preservación; y además, que cumple con los requisitos correspondientes para ser incluido en la Lista de Patrimonio Mundial de la UNESCO. La información y promoción sobre este monumento beneficia la industria turística de la zona.
\end{abstract}

Palabras clave: Monasterio de Tholing, murales, arte tibetano, patrimonio cultural, turismo.

\begin{abstract}
Tholing Monastery is one of the most important religious monuments in western Tibet, and its murals show the greatest artistic achievement of the Tibetans in the cultural and aesthetic context in the two different periods of Tibetan history. This article first introduces the historical context of this monument, indicating its importance in the development of Tibetan history. Secondly, both the historical and artistic value of the murals of the Tholing Monastery are explained and it is suggested that this monument deserves more attention in preservation and research, and should be included in the UNESCO World Heritage List. Finally, it is considered that the tourist use of the Tholing Monasteries and its Buddhist frescoes could contribute in the future to promote the tourism industry in that area.
\end{abstract}

Keywords: Tholing Monastery, murals, Tibetan art, cultural heritage, tourism.

Este es un artículo Open Access bajo la licencia Creative Commons AtribuciónNoComercial-Compartirlgual 4.0

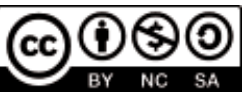




\section{Introducción}

La cultura única del Tíbet atrae la atención de los exploradores, eruditos y viajeros. Ngari y el Reino perdido de Guge, en el límite oeste de la meseta, son siempre una leyenda fascinante. La existencia del Reino de Guge tiene un significado muy importante en la historia de Tíbet, especialmente la referida al budismo tibetano y la expresión artística.

Sin embargo, los registros de este próspero reino budista aparecen muy fragmentados. Son pocos los documentos encontrados, por lo que se puede explorar la historia de este reino perdido mediante las ruinas encontradas en el oeste del Himalaya donde se conservan unos murales impresionantes.

En los últimos años el interés del mundo occidental por el Tíbet y la expresión artística de este antiguo reino desaparecido es cada vez mayor. Los murales conservados en los templos representan el mayor logro de este tipo de arte, también son una prueba del intercambio entre Tíbet y los círculos culturales que lo rodean. Además, estos frescos son testimonio de la transmisión cultural, la estética y la devoción infinita a los dioses mediante los murales bajo un entorno natural extremo.

El Monasterio de Tholing es el más antiguo y representativo de todos los templos de Guge y sus murales son los que mejor se conservan. Precisamente, por ese gran valor artístico e histórico, se considera que cumplen con las condiciones para ser incluidos en la Lista de Patrimonio Mundial de la UNESCO.

El proceso metodológico para llevar a cabo el estudio consistió, en primer lugar, en una visita para recoger datos producto de la observación directa; en segundo lugar, en una exhaustiva revisión bibliográfica sobre la relevancia histórico-artística del objeto de estudio y su contextualización espacio-temporal; y en tercer lugar, en la revisión de la documentación para ser considerado por UNESCO como un patrimonio mundial, y por ende, contar con el financiamiento para su conservación y protección.

El objetivo es contribuir con la información y conocimiento que se tiene sobre estos frescos budistas que por su emplazamiento son desconocidos, incluso por especialistas en historia del arte. Además, gracias a la información, en la que se destaca su valor, se promueve el turismo cultural en favor de la región.

\section{Panorama general del Monasterio de Tholing}

El Monasterio de Tholing fue construido en el año 996 por Yeshe-Ö del Antiguo Reino de Guge ${ }^{1}$ (s. X-XII), y constituyó a lo largo de la historia uno de los centros de difusión más importantes del budismo tibetano, y por lo tanto, tuvo un papel decisivo en la historia de la región del Tibet (Du, 2011).

El complejo contiene varios edificios, entre los que destacan el Tsugla Khang (Templo de Yeshe-Ö) con sus pagodas periféricas al noreste y noroeste; el Serkhang; el Lhakhang Marpo (el Templo Rojo) y el Lhakhang

\footnotetext{
1 El antiguo Reino de Guge era un antiguo reino en el oeste del Tíbet (desde el siglo X hasta el siglo XII). Su región incluye el actual distrito Ngari en Tíbet y áreas como Zanskar, Kinnaur Superior, Lahul y Spiti en India.
} 


\section{Figura 1}

Panorámica del Monasterio de Tholing

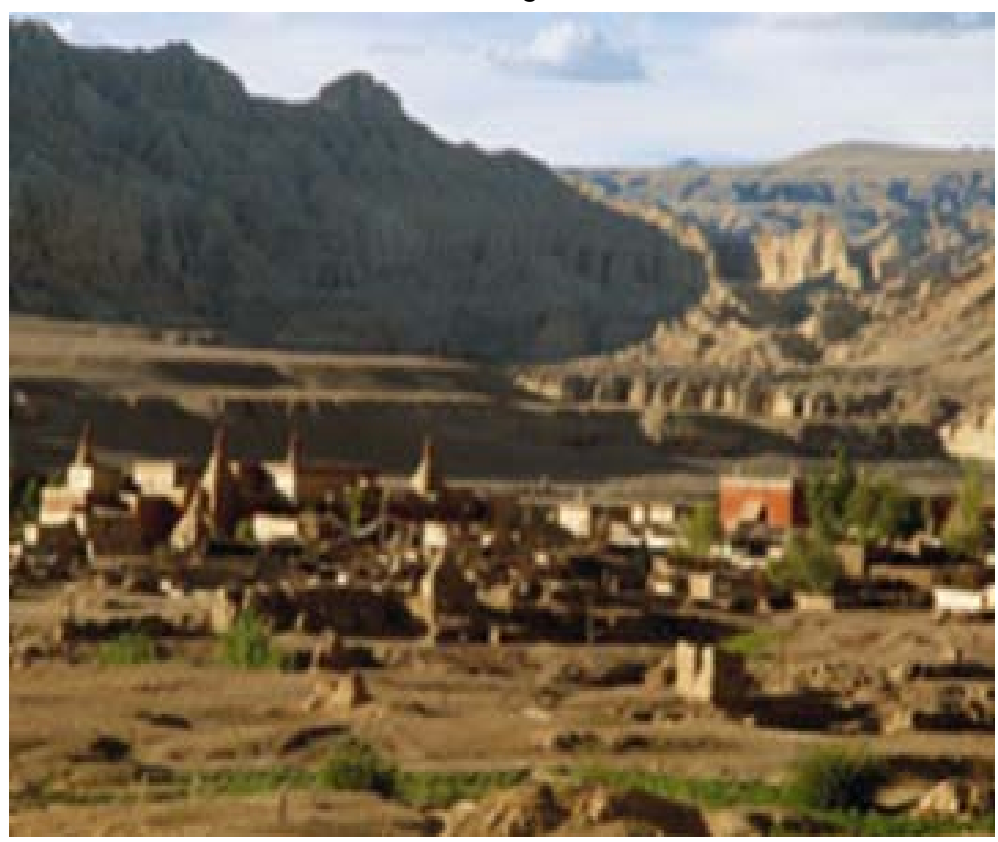

Nota. Fotografía de Zhang Chaoyin.

Karpo (el Templo Blanco), así como otras dependencias menores. Todos estos templos estaban cubiertos originalmente con pinturas murales de alto valor histórico y artístico, algunas de las cuales aún se conservan.

El edificio más antiguo del monasterio es el Tsugla Khang, cuya construcción junto con las dos pagodas que lo acompañan y el Serkhang, se completó en el periodo del Antiguo Reino de Guge a finales del siglo X. El concepto arquitectónico de Tsugla Khang parece ser un mandala gigante y el Serkhang es, según la leyenda, el lugar donde el maestro Rinchen Zangpo meditó en sus últimos años.

Desafortunadamente, estos dos templos en la actualidad están destruidos, y solo se preservan algunos murales fechados en el siglo XI, en las dos pagodas que acompañan al templo. Esos murales, por su estética propia de Cachemira y Asia Central, fueron pintados probablemente por artesanos originarios de esas zonas a principios del siglo XI, y sus manifestaciones son distintas al arte tibetano original (Van Ham, 2016, pp. 216-217).

El Lhakhang Marpo (el Templo Rojo) y el Lhakhang Karpo (el Templo Blanco) fueron construidos en el siglo XV, durante el periodo del Nuevo Reino de Guge ${ }^{2}$ (s. XV-XVII).

2 Nuevo Reino de Guge era un antiguo reino en el oeste del Tíbet (desde el siglo XV hasta el siglo XVII). 


\section{Figura 2}

Mural en la pagoda noroeste del Monasterio de Tholing, siglo XI

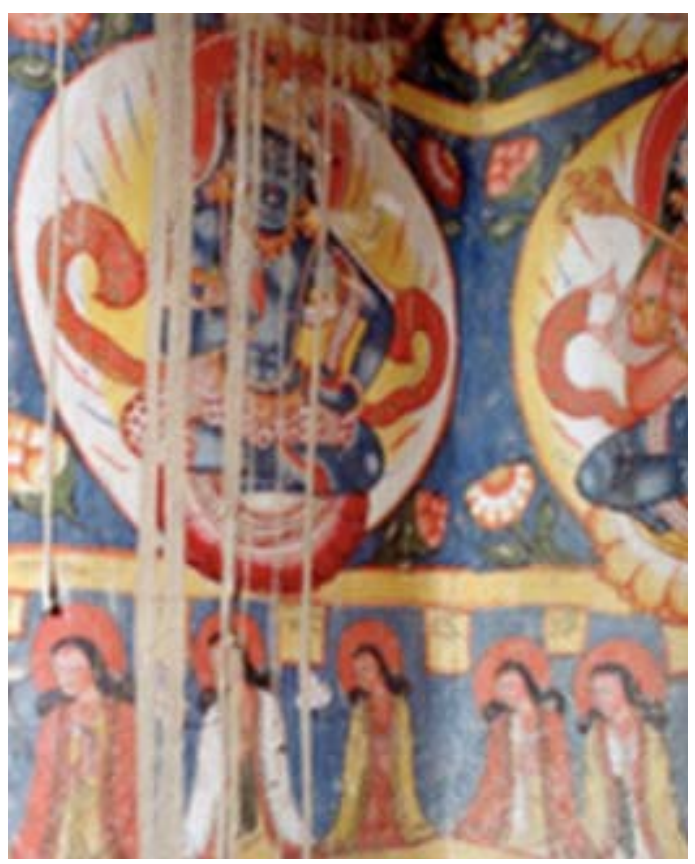

Nota. Fotografía de Zhang Chaoyin.

El Templo Rojo cuenta con murales bien conservados cuya temática se centra en las prácticas del Yoga Tantra y que, según algunos investigadores, imitan al estilo de los murales del siglo XI. Los contenidos de estos frescos incluyen estatuas budistas, figuras históricas y escenas de asambleas, un estilo heredado de la tradición de Cachemira en el oeste del Himalaya. Además, los murales del Templo Blanco reflejan la estética clásica del estilo de Guge, que incluyen figuras de personajes importantes y deidades de la historia de Guge, de finales del siglo XV.

La característica más destacada del arte del Nuevo Reino de Guge en el siglo XV radica en la incorporación de muchos elementos estéticos de Cachemira a las obras de estilo tibetano y nepalés. La familia real del Nuevo Reino de Guge pretendía, mediante esta expresión visual, una conexión con la Edad de Oro del Antiguo Reino de Guge 400 años atrás (Chen, 2017; Kerin, 2015).

Debido a que el Antiguo Reino de Guge reinstauró el budismo en Tibet, el Tholing se convirtió gradualmente en el centro religioso del reino, en el que habitaba y trabajaba Rinchen Zangpo, famoso maestro traductor del budismo tibetano. También fue el lugar desde el cual el maestro Atisha, procedente de India, difundió el budismo primero por el oeste de Tíbet y luego por todo el resto de la región. Por lo tanto, Tholing, se puede considerar como uno de los lugares del nacimiento de la segunda difusión del budismo tibetano, determinante para el devenir histórico posterior del Tíbet. Hasta el siglo XV, la familia real del Nuevo Reino de Guge (del siglo XV al siglo XVII) reconstruyó y amplió el monasterio, cuyas ruinas son las que se pueden ver ahora. 


\section{Figura 3}

Murales en el Lhakhang Marpo (el Templo Rojo) de Tholing, finales del siglo XV

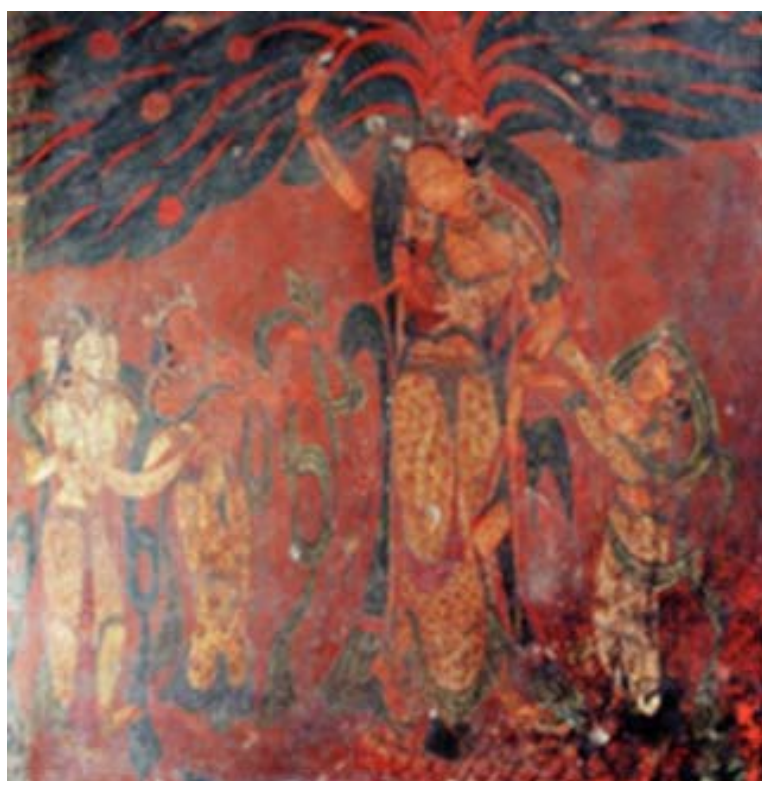

Nota. Fotografía de Zhang Chaoyin.

Refleja la prosperidad del budismo en el Nuevo Reino de Guge del siglo XV. Claramente, se revive la estética de Cachemira que había sido popular en el oeste de Himalaya cientos de años atrás.

\section{Figura 4}

Murales en el Lhakhang Marpo (el Templo Rojo) de Tholing, finales del siglo XV

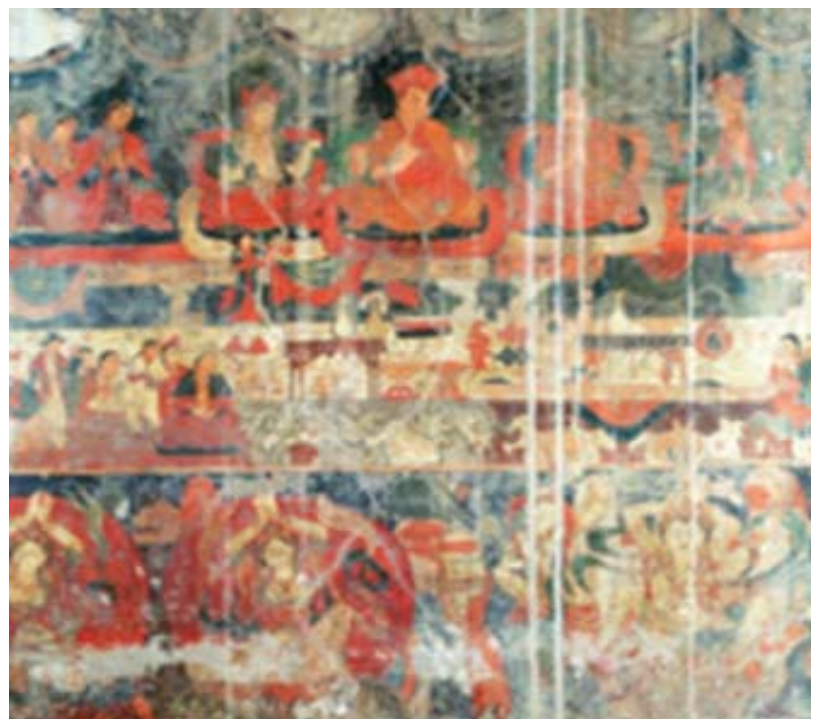

Nota. Fotografía de Zhang Chaoyin.

Refleja la prosperidad del budismo en el Nuevo Reino de Guge del siglo XV. Claramente, se revive la estética de Cachemira que había sido popular en el oeste de Himalaya cientos de años atrás. 


\section{Criterios de selección para incluir el Tholing como patrimonio de la humanidad}

En el Tíbet existen muchos patrimonios con alto valor artístico e histórico que merecen ser estudiados y protegidos. Sin embargo, en todo el Tíbet, solo el conjunto histórico del Palacio del Potala en Lhassa es considerado por la UNESCO como patrimonio de la humanidad. Aunque en los últimos años, el interés del mundo occidental por el Tíbet y su única cultura es cada vez mayor. No se conoce el Tholing y su arte, por tanto, no se conoce su alto valor. En el presente estudio, se plantea que debe ser incluido en la Lista de Patrimonio de la Humanidad de UNESCO, y de esta manera obtener apoyo para su protección e investigación.

\section{Regulaciones de la UNESCO}

De acuerdo al artículo n. ${ }^{\circ} 1$ de la Convención sobre la protección del patrimonio mundial, cultural y natural (UNESCO, s.f.), se considera como patrimonio cultural a los monumentos o los conjuntos que tienen un valor universal excepcional desde el punto de vista de la historia, del arte o de la ciencia. También, se señala que son los lugares que tienen un valor universal excepcional desde el punto de vista histórico, estético, etnológico o antropológico.

Para determinar si un patrimonio cultural tiene el valor universal excepcional se debe cumplir con, por lo menos, uno de los seis criterios que se plasman en el artículo II. D. 77 de las Directrices operativas para la implementación de la Convención del Patrimonio Mundial (UNESCO, 2019):

1. Representar una obra maestra del genio creativo humano.

2. Testimoniar un importante intercambio de valores humanos a lo largo de un periodo de tiempo o dentro de un área cultural del mundo, en el desarrollo de la arquitectura, tecnología, artes monumentales, urbanismo o diseño paisajístico.

3. Aportar un testimonio único o al menos excepcional de una tradición cultural o de una civilización existente o ya desaparecida.

4. Ofrecer un ejemplo eminente de un tipo de edificio, conjunto arquitectónico, tecnológico o paisaje, que ilustre una etapa significativa de la historia humana.

5. Ser un ejemplo eminente de una tradición de asentamiento humano, utilización del mar o de la tierra, que sea representativa de una cultura (o culturas), o de la interacción humana con el medioambiente especialmente cuando este se vuelva vulnerable frente al impacto de cambios irreversibles.

6. Estar directa o tangiblemente asociado con eventos o tradiciones vivas, con ideas o con creencias, con trabajos artísticos y literarios de destacada significación universal. 


\section{Determinación de selección}

El complejo del Monasterio de Tholing y sus murales (siglos XI a XV) reflejan la prosperidad del Antiguo Reino de Guge y Nuevo Reino de Guge en la zona Ngari del antiguo Tíbet y constituye, además, un hito importante en el desarrollo del budismo tibetano.

Los edificios y murales terminados alrededor del siglo XI son testigos importantes de la primera etapa de la segunda difusión ${ }^{3}$ del budismo en el Tíbet, mientras que los del siglo XV, son testigos del renacimiento ${ }^{4}$ del arte budista tibetano. Todos estos murales religiosos existentes reflejan el concepto estético y la creencia de aquella época. Por lo tanto, las ruinas del Monasterio de Tholing son un conjunto excepcional, que representa una tradición cultural y la trasferencia de valores y tradiciones estéticas, y que ilustra una etapa significativa de la historia humana y de una tradición cultural; cumpliendo con los requisitos del artículo n. ${ }^{\circ}$ de la Convención sobre la protección del patrimonio mundial, cultural y natural.

Además, el Tholing cumple con los puntos primero, segundo, tercero y sexto del artículo II. D. 77 de la Operational Guidelines for the Implementation of the World Heritage Convention.

\section{Punto primero del artículo $n .^{\circ} 77$}

\section{Representar una obra maestra del genio creativo humano.}

Los murales del siglo XI del Monasterio de Tholing representan los elementos de arte de Cachemira, heredados del arte de Gupta ${ }^{5}$ que integra elementos de Persia y Asia Central. Con ellos surge un estilo único, muy diferente del arte de otras regiones debido a su ubicación geográfica. De acuerdo con la investigación, es probable que los primeros murales de las dos pagodas de Tholing hechos por los artesanos de Cachemira, sean los únicos que quedan en la Región Autónoma del Tíbet (Chen, 2018). Por lo tanto, estos murales pueden considerarse como una prueba del intercambio cultural entre el Antiguo Reino de Guge (Tíbet) y Cachemira, al comienzo de la segunda difusión del budismo. Estos murales budistas tienen un gran valor como patrimonio de la estética de Cachemira en Tíbet debido a su rareza y escasez, porque con la expansión musulmana hacia Cachemira en el siglo XII, este tipo de expresión artística se fue extinguiendo.

Los murales del siglo XV del Monasterio de Tholing son obras representativas del arte del Nuevo Reino de Guge. En estas obras, los artistas adoptan las notables expresiones estéticas de Cachemira basadas en la estética nepalesa y tibetana de aquella época. El estilo de Cachemira fue popular en el Antiguo Reino de Guge desde el siglo X hasta el siglo XII, sin embargo, desde la segunda mitad del siglo XII hasta el siglo XIV, este tipo de expresión artística se fue extinguiendo. Según algunos historiadores de arte, los elementos estéticos de Cachemira aparecen deliberadamente en las obras de arte del estilo de Guge del siglo XV, para conectar ambos reinos (Chen, 2018; Kerin, 2015). El arte del estilo de Guge incorpora elementos estéticos ajenos al entorno.

\footnotetext{
3 Un movimiento de la reinstauración del budismo organizado por todos los líderes y templos en todo Tíbet después de la persecución budista por el último emperador del Imperio tibetano, Langdarma al final del siglo IX.

4 Esta palabra generalmente indica que, después del siglo XV, el desarrollo del arte tibetano comienza a formar una nueva etapa: desde la imitación estética y los elementos de otras culturas hasta el desarrollo de los estilos nacionales indígenas. El arte del Nuevo Reino de Guge del siglo XV es un ejemplo.

5 Reino Gupta: La época de esplendor de la India antigua.
} 


\section{Figura 5}

Mural en la pagoda noroeste, siglo XI

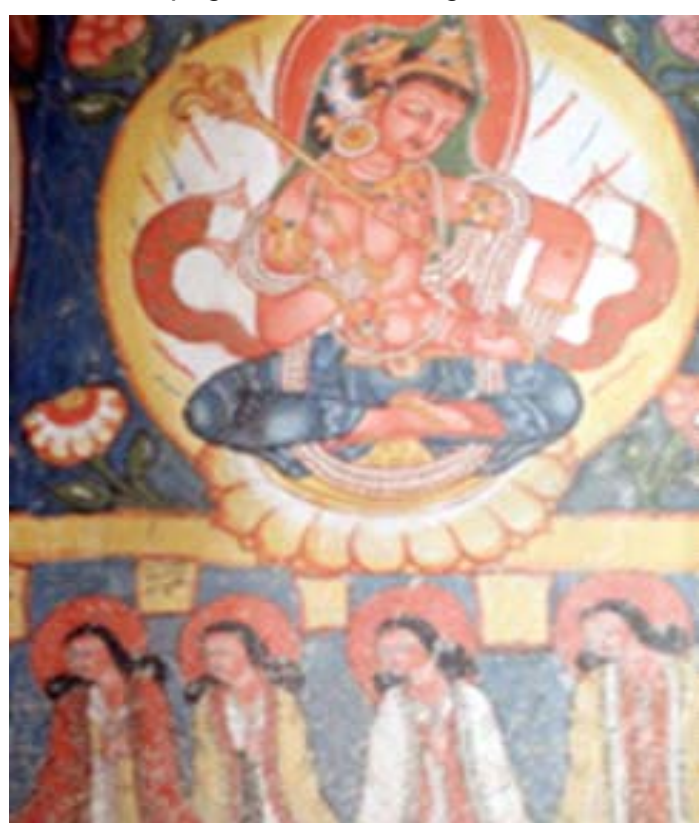

Nota. Fotografía de Zhang Chaoyin.

Los murales en las dos pagodas son probablemente la única evidencia que muestran las actividades de los artistas de Cachemira en el Tíbet, que junto con la Figura 2, representan las características de la estética de Cachemira, principal recurso artístico del arte del Antiguo Reino de Guge, representando a las deidades, especialmente a las diosas, de una manera más dinámica y apasionada en comparación con otros estilos de pintura tibetanos.

\section{Figura 6}

Mural en el Lhakhang Marpo (el Templo Rojo), finales del siglo XV

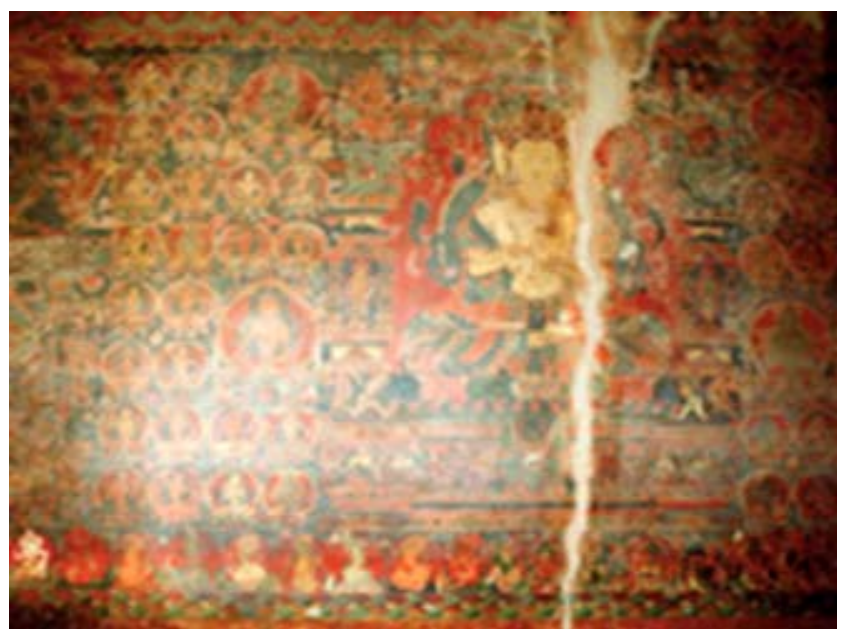

Nota Fotografía de Zhang Chaoyin.

Con la esperanza de conectar visualmente con el estilo artístico del Antiguo Reino de Guge del siglo X al siglo XII, los artistas del Nuevo Reino de Guge del siglo XV incluyeron en sus murales muchos elementos de las pinturas antiguas de Cachemira. 


\section{Figura 7}

Decoración de los techos del Lhakhang Marpo (el Templo Rojo), finales del siglo XV

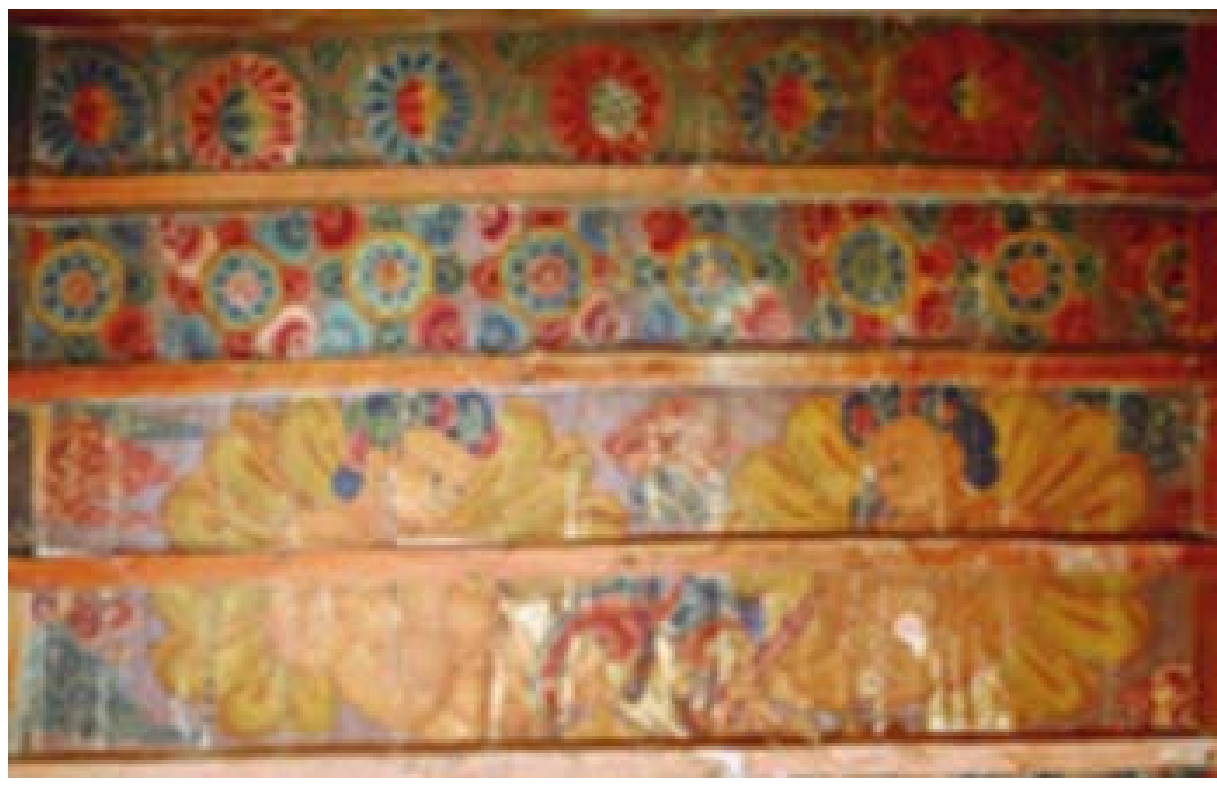

Nota. Fotografía de Zhang Chaoyin.

La decoración de los techos del Monasterio de Tholing es un reflejo artístico multicultural. Aquí se mezclan los elementos

artísticos de Persia, Cachemira, China y local; por lo tanto, se crea una manifestación visual distinta.

\section{Punto segundo del artículo n. ${ }^{\circ}$ 77:}

Testimoniar un importante intercambio de valores humanos a lo largo de un periodo de tiempo o dentro de un área cultural del mundo, en el desarrollo de la arquitectura, tecnología, artes monumentales, urbanismo o diseño paisajístico.

El Tholing sirvió como centro religioso desde el cual se expandió el budismo. Sus murales son muy representativos de la estética de la época y tuvieron gran influencia, y por tanto, tienen una posición muy importante en la discusión de la historia del arte tibetano. Los murales al estilo de Cachemira dentro de las dos pagodas son un punto importante en la historia del arte; testifican el proceso de la difusión de este estilo de Cachemira (Valle de Srinagar) al oeste del Tíbet. Después de esto, los artistas en el oeste del Tíbet comenzaron a estudiar e imitar esta forma artística y al final crearon un estilo artístico local; son ejemplo, los primeros frescos del Monasterio de Tabo de Himachal Pradesh ubicado en India.

Por otra parte, los murales de Lakhang Marpo y Lakhang Karpo de Tholing son obras típicas del estilo Guge en el periodo del Nuevo Reino de Guge, estilo que sirve como punto de referencia estético en aquella época y que influye profundamente en el arte posterior de la región. Como ejemplo de frescos, se mencionan a los últimos de los templos de Tsaparang y del Monasterio de Tabo. Como ejemplo de pinturas, se mencionan al Thangka de Buda Sakiamuni, que ahora está depositada en el Museo de Bellas Artes de Virginia. 


\section{Punto tercero del artículo n. ${ }^{\circ} 77$}

Aportar un testimonio único o al menos excepcional de una tradición cultural o de una civilización existente o ya desaparecida (ver Figura 2 y 5 para los casos del Antiguo Reino de Guge y Figura 3, 4, 6, 7 y 8 para los casos del Nuevo Reino de Guge).

Con la desaparición del Antiguo Reino de Guge y el Nuevo Reino de Guge, los frescos conservados en las ruinas del Monasterio de Tholing son testigos de una civilización perdida; con lo que el estilo del arte único heredado de Cachemira y desarrollado en estos dos periodos desapareció. De hecho, después del siglo XVII, lo que en un tiempo era considerado arte tibetano fue gradualmente unificándose con el estilo Menri apoyado por la Gelugpa ${ }^{6}$ en el centro del Tíbet.

\section{Figura 8}

Escena de la asamblea en el mural del Lhakhang Marpo (el Templo Rojo), finales del siglo $\mathrm{XV}$

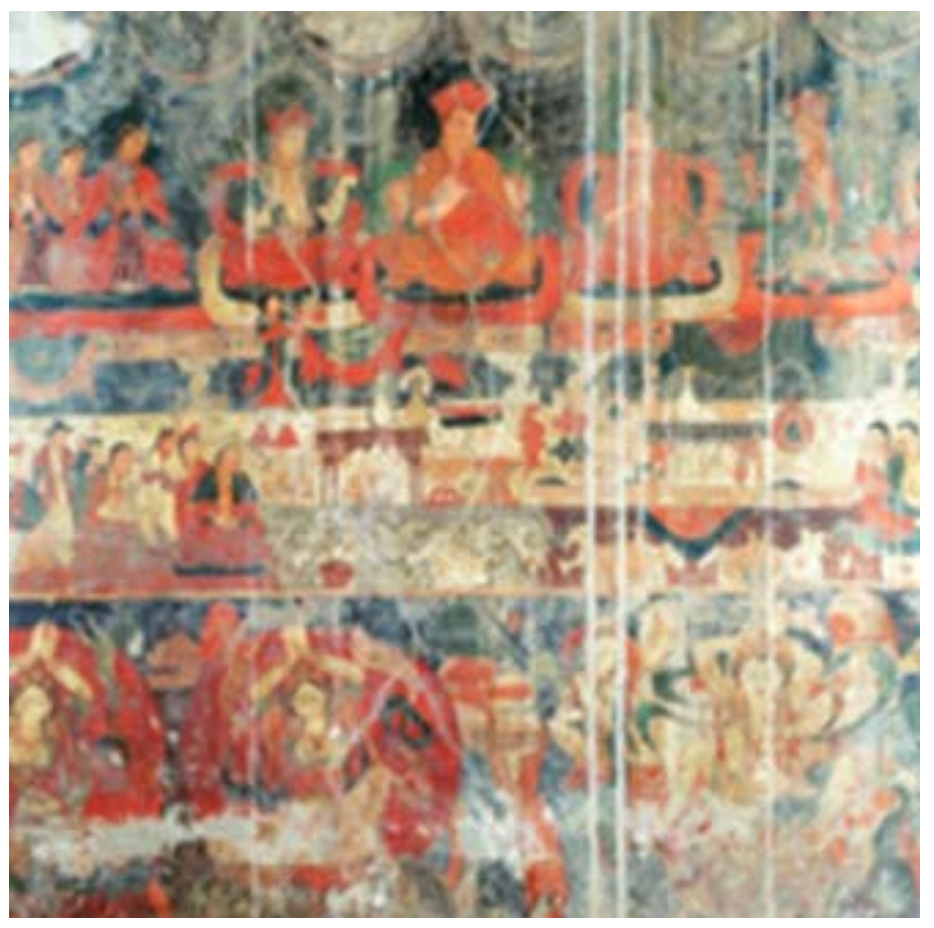

Nota. Fotografía de Zhang Chaoyin.

La característica habitual del arte del oeste del Himalaya refleja escenas de actividades religiosas de la vida social de la gente común, de la familia real de Guge, de visitantes extranjeros y de la prosperidad de la época. También, proporciona pistas para conocer la moda y costumbres de aquel momento.

6 Gelugpa es la escuela más importante del budismo tibetano hasta hoy. 


\section{Punto sexto del artículo n. ${ }^{\circ} 77$}

\section{Estar directa o tangiblemente asociado con eventos o tradiciones vivas, con ideas o con creencias, con trabajos artísticos y literarios de destacada significación universal.}

El Tholing sirve como el templo origen del budismo tibetano en la región del oeste de Himalaya, su historia y arte reflejan muchos eventos importantes en la historia tibetana. Los edificios y frescos del Tholing en el siglo XI representan la reinstauración del budismo en el Antiguo Reino de Guge y muestran el inicio de la segunda difusión del budismo tibetano. Su fundador Yeshe-Ö, tiene una notable y noble posición en la historia del Tíbet. El gran maestro Rinchen Zangpo, traductor y promotor del inicio de la segunda difusión del budismo, quien además estableció una importante conexión entre Tíbet y Cachemira, centro del budismo en aquella época. El Maestro Atisha invitado al Tholing para promover el budismo y organizar el sistema del monasterio tibetano, también es considerado como patriarca por las escuelas budistas Kadampa y Gelugpa, la escuela principal del budismo tibetano actual.

Los edificios y frescos de Tholing en el siglo XV simbolizan el renacimiento del arte budista tibetano. Este renacimiento estaba relacionado con una nueva escuela, Gelugpa. En aquel momento, un discípulo del fundador de la Gelugpa fue al oeste del Tíbet para solicitar el apoyo de la familia real del Nuevo Reino de Guge para hacer frente a otros regímenes y escuelas del centro del Tíbet. En los frescos de Tholing se pueden ver muchas referencias de esa colaboración. Reflejando el contexto religioso y político en el oeste de Tíbet de la época.

Como resultado de este análisis, sobre el valor artístico e histórico del Monasterio del Tholing, se llega a la conclusión que se cumple, con por lo menos, cuatro criterios del artículo n. ${ }^{\circ} 77$ de la Operational Guidelines for the Implementation of the World Heritage Convention. Es decir, el Monasterio de Tholing tiene un valor universal excepcional y cumple los criterios para ser seleccionado como patrimonio cultural mundial.

\section{Proyectos de las autoridades chinas para la preservación del Monasterio de Tholing}

El Monasterio de Tholing ha sufrido varias destrucciones por fenómenos naturales y otras provocadas por el hombre. Algunos templos afortunadamente mantienen su apariencia original porque fueron utilizados como almacenes. En los últimos años, con la comprensión gradual del valor de los bienes culturales, las autoridades chinas e instituciones de investigación académica continúan protegiendo y estudiando el Monasterio de Tholing, resaltando el valor histórico único e importante del Monasterio de Tholing.

En el año 1996, de acuerdo con el artículo n. ${ }^{\circ} 13$ de la Ley de Protección de Reliquias Culturales de la República Popular de China, se designó al Monasterio de Tholing como «Sitio de Patrimonio Clase A bajo protección estatal» (Chun, 2018). Este es el nivel más alto de la conservación del patrimonio cultural en China.

En el año 2015, el grupo de trabajo de arqueología digital del Instituto de Patrimonio Cultural de la Universidad de Zhejiang colaboró con la Oficina Cultural de Ngari y la Oficina de Patrimonio de Zanda en Tíbet, para holografiar digitalmente con alta precisión los murales del Templo Blanco (el Lhakhang Karpo) del Monasterio de Tholing, obteniendo datos informativos de las imágenes que no se hubieran podido lograr por medio de los 
métodos tradicionales de fotografía (Wei, 2016). Así, se puede ver el ascenso y la caída de cada línea en la pintura. Mediante esta técnica, incluso si los murales fueran dañados de manera irreversible, se podrían restaurar, basados en la información original guardada.

Adicionalmente, la Universidad de Zhejiang publicó un álbum, en tibetano, chino e inglés, con los resultados arqueológicos y tecnológicos; titulado Los frescos de Ngari: el templo blanco (Zeng y Liu, 2016).

\section{Perspectivas para el turismo en el Monasterio de Tholing}

Ngari, donde se encuentra el Monasterio de Tholing, está ubicado en el punto más occidental del Tíbet. Su industria turística aún está en la etapa inicial, no solo está limitado por el gobierno local, sino también por insuficientes infraestructuras (transportes y alojamientos) y la escasez de promociones turísticas. De hecho, esta región tiene abundantes recursos turísticos, es un complejo que combina paisaje, cultura y religión.

La región de Ngari es conocida por sus montañas y lagos, y tienen un significado religioso para el hinduismo y el budismo. Las cordilleras del Himalaya y Gangdise atraviesan esta región. El Monte Kailash de Gangdise ha sido considerado durante mucho tiempo como el centro del mundo para budistas, hindúes y jainistas, lo que le da un fuerte simbolismo cultural. Por otra parte, el otro pico alto del Himalaya occidental-Gurla Mandhata, todavía hoy es considerado como una diosa. El Mapham Yutso, es el lago de agua dulce más alto del mundo, figurando como uno de los tres lagos sagrados en la religión y la leyenda tibetana. Estos paisajes naturales, combinados con la cultura local y sus religiones, conforman una región geográfica sagrada con enorme significado espiritual y cultural, atrayendo continuamente peregrinos.

Además, como se ha mencionado, el Condado de Purang, el Guge y otras áreas de Ngari son el origen del Reino de Guge, donde se encuentra gran cantidad de patrimonio cultural tales como templos, palacios y grutas etc., el más conocido: el Monasterio de Tholing, objeto de este estudio. Desde la desaparición del Reino Guge en el siglo XVII, estas ruinas aún dejan muchos misterios sin resolver, esperando a ser descubiertos. En particular, sus murales hacen que estos sitios sean museos vivos. Estas características fomentan que Ngari tenga un gran potencial para convertirse en un destino turístico.

El modelo turístico basado en el concepto de antigua civilización perdida, sumado a los paisajes naturales locales, tiene éxito en muchas partes del mundo, tales como el Cuzco y Machu Picchu en la cordillera de los Andes del Perú y la península de Yucatán en México. Por consiguiente, combinando la historia y leyenda del Reino de Guge, el Monasterio de Tholing y las ruinas de Guge, con paisajes naturales circundantes, es posible convertir la región de Ngari en una zona turística icónica. Por supuesto, el desarrollo del turismo debe considerar simultáneamente el respeto y el equilibrio entre la cultura local y la protección ecológica del entorno, y eso depende de una planificación detallada entre el gobierno local y los profesionales idóneos.

Paralelamente, es importante investigar y trabajar en la conservación de los monumentos históricos en relación con la vida social y costumbres de los residentes locales, ya que en algunos casos pueden presentarse conflictos. Los monasterios no son solo sitios religiosos, también son centros sociales que tienen múltiples significados y 
funciones para los tibetanos. Designar templos o monasterios como monumentos históricos significa que los templos pierden su función original en cierta medida, y que su uso diario de los pobladores locales queda muy restringido. Además, en la tradición tibetana, mantener los murales de los templos con una apariencia completamente nueva y realizar ciertas reparaciones es la forma local de expresar respeto por los dioses, lo que resulta contradictorio con el concepto de conservación de monumentos históricos, que es mantener la apariencia original de los murales tanto como sea posible. Solucionar todos estos problemas depende de la comunicación abierta, sincera y efectiva entre las entidades relevantes y los residentes locales.

\section{Conclusiones}

El objetivo del presente trabajo es analizar las condiciones para que el Monasterio de Tholing se incluya en la Lista de Patrimonio Mundial de la UNESCO. De acuerdo con los tres puntos del artículo n. ${ }^{\circ} 1$ de la Convención sobre la protección del patrimonio mundial, cultural y natural, el Monasterio de Tholing y sus murales reflejan los dos períodos importantes: el periodo del Antiguo Reino de Guge y el del Nuevo Reino de Guge, del desarrollo del budismo tibetano y la historia de Tíbet; también, muestra la estética de la época, por lo que es un monumento de alto valor histórico y artístico.

Además, el Monasterio de Tholing y sus murales cumplen con, por lo menos, cuatro puntos del artículo II.D. 77 de la Operational Guidelines for the Implementation of the World Heritage Convention. Vale decir, pertenece a un logro artístico único y tiene cierta influencia en el campo del arte; asimismo, aporta con el testimonio de una civilización o tradición cultural desaparecida, vinculada a hechos históricos importantes. Por tanto, el Monasterio de Tholing tiene un valor universal excepcional.

Finalmente, se extiende el debate sobre los puntos que UNESCO considera para incluir a nuevos objetos en la Lista de Patrimonio de la Humanidad y se exponen las perspectivas del turismo acerca del Monasterio de Tholing y su zona circundante. Se integra naturaleza, cultura y religión; tiene un gran potencial para convertirlo en un destino turístico icónico. 


\section{Referencias}

Chen, P. Y. (8 de julio de 2017). The Guge RevivalÿThe origin of the 15th century Guge style of West Himalayas. Sohu.com. http:// m.sohu.com/a/162829001_687796

Chen, P. Y. (26 de febrero de 2018). Tholing Monastery revisit. Sohu.com. http://www.sohu.com/a/224179839_687796

Chun, L. (10 de octubre de 2018). Información Cultural. VTibet.com. http://www.vtibet.cn/wh/

Du, L. (22 de marzo de 2011). El reino tibetano de Guge, una tierra remota cerca del cielo. spanish.china.org.cn. http://spanish.china.org.cn/ photos/txt/2011-03/22/content_22194882.htm

Kerin, M. (2015). Art and Devotion at a Buddhist Temple in the Indian Himalaya, Indiana University Press.

UNESCO. (s.f.). Convención sobre la protección del patrimonio mundial, cultural y natural. https://whc.unesco.org/en/conventiontext/

UNESCO. (2019). Operational Guidelines for the Implementation of the World Heritage Convention. https://whc.unesco.org/en/ guidelines.

Van Ham, P. (2016). Guge-Age of Gold, The West-Tibet Masterpieces. Hirmer Verlag.

Wei, J. J. (22 de setiembre de 2016). Protección digital de reliquias culturales en Tibet Expo: murales del templo de Tuolin que puedes llevarte a casa. kknews. https://kknews.cc/culture/3452qg.html

Zeng, F. Q. y Liu, J. (15 de julio de 2016). Expertos de la Universidad de Zhejiang recopilan digitalmente murales tibetanos en Ali. Noticias de Zhejiang. https://zj.zjol.com.cn/news.html?id=395924

Yin Li

Grado en Dirección Turística de la Universidad de la Ciudad de Beijing, China de 2007 a 2011. Máster en Gestión y Liderazgo de Proyectos Culturales en la Universidad Rey Juan Carlos (Madrid) 2011-2012. Máster en Dirección Turística Internacional en la Universidad Rey Juan Carlos (Madrid) 2012-2014. En la actualidad está realizando un doctorado interuniversitario en Turismo en la Universidad Rey Juan Carlos. Publicaciones: Los museos españoles: ¿Son o no un incentivo cultural para los turistas chinos?; Museos y Marketing: una controversia ante nuevas estrategias (publicado en abril de 2020).

sofia_1212@163.com

ORCID: 0000-0002-1710-8275 